\title{
Evolution of superficial spreading melanoma to resemble desmoplastic melanoma: case report
}

\author{
Martin G. Cook ${ }^{1,2,3}$ - Barry W. E. M. Powell ${ }^{4}$ - Megan E. Grant ${ }^{2} \cdot$ Adele C. Green $^{2,5}$ \\ Received: 11 March 2021 / Revised: 29 April 2021 / Accepted: 2 May 2021 / Published online: 20 July 2021 \\ (C) Crown 2021
}

\begin{abstract}
Desmoplastic melanoma commonly occurs on the head and neck in a pure form, but occasionally, it occurs in a mixed tumor with another type, usually superficial spreading melanoma (SSM), and rarely as a metastasis from a primary SSM. We report here a primary SSM on the leg of a 32-year-old male which metastasised to lymph nodes, and 10 years later recurred at the primary site initially with mixed features but evolving to resemble a uniformly desmoplastic, deeply invasive melanoma. This unusual case has implications for clinical management and is additionally notable for its reversal in behavior, from metastatic to local infiltrative type, correlating with the change in morphology.
\end{abstract}

Keywords Desmoplastic melanoma $\cdot$ Superficial spreading melanoma $\cdot$ Mixed desmoplastic $\cdot$ Tumor behavior reversal

Desmoplastic melanoma most commonly occurs on the head and neck as a poorly circumscribed dermal mass and tends to recur locally rather than metastasise [1]. It usually occurs in pure form but occasionally is seen as a desmoplastic component of a mixed tumor with the other element being a lentigo malignant melanoma (LMM) or superficial spreading melanoma (SSM) type and behavior then relates to the more aggressive component [2]. Very rarely a metastasis from SSM occurs as a desmoplastic lesion $[3,4]$. We describe here a

Martin G Cook and Barry W. E. M Powell are members of the EORTC Melanoma Group.

Martin G. Cook

m.cook@nhs.net

1 Department of Histopathology, Royal Surrey County Hospital, Egerton Road, Guildford GU2 7XX, UK

2 Molecular Oncology Group, Cancer Research UK Manchester Institute, University of Manchester, Wilmslow Road, Manchester M20 4BX, UK

3 Division of Clinical Medicine, University of Surrey, Guildford GU2 7XH, Surrey, UK

4 Department of Plastic and Reconstructive Surgery, St. George's Hospital, Blackshaw Road, Tooting, London SW17 0QT, UK

5 QIMR Berghofer Medical Research Institute, Brisbane, QLD 4006, Australia primary melanoma of clear SSM phenotype which metastasised to lymph nodes and showed in-transit metastases, but 10 years later recurred near the scar at the primary site with mixed conventional and desmoplastic features and then progressed to resemble a completely desmoplastic, deeply invasive melanoma at the original site. We believe it important to record this unusual case as it has implications for clinical management. In addition, we note that the reversal in aggressive behavior from metastatic to local infiltrative type was correlated with the change in morphology.

\section{Case report}

In 2005, a male aged 32 years was referred by his general practitioner to a plastic surgeon with a newly acquired pigmented lesion on the left calf suspected to be melanoma. This was excised and histologically diagnosed as SSM, 1.5$\mathrm{mm}$ thick, with mitotic count $6 / \mathrm{mm}^{2}$. It was widely excised and sentinel node biopsy was performed. Two sentinel nodes from the left groin both contained a parenchymal metastasis $0.2 \mathrm{~mm}$ in maximum dimension. The melanoma was shown to have a $\mathrm{BRAF}^{\mathrm{V} 600 \mathrm{E}}$ mutation.

In the same year, 2005, the patient had six clinically benign moles on the mid- and upper back excised, one of which was histologically melanoma in situ. In 2008, three further pigmented lesions were removed from the left anterior calf, left lateral thigh, and left anterior shin. 
All were confirmed as benign junctional naevi, completely excised. However, in 2009, 4 years after diagnosis of the primary SSM, the patient found a nodule in the upper left popliteal fossa. Histology showed completely excised metastatic melanoma. In 2011, 6 years after diagnosis of the primary SSM, new pigmentation was noted adjacent to the original scar, and on excision was histologically diagnosed as a junctional naevus with dysplasia without a dermal component (Figs. 1, 2, 3).

In 2015, 10 years after excision of the primary SSM on the calf, three subcutaneous nodules were identified near the original scar. On excision, these were shown to be recurrent melanoma with an epithelioid component similar to the original, but merging with a spindle cell desmoplastic component. The deeper spindle desmoplastic component was S100-positive but HMB45-negative, in contrast to the original melanoma which was HMB45-positive.

In August 2016, a further subcutaneous lesion was identified on the left calf underlying the previous scar. This was excised and described histologically as spindle cell recurrent melanoma. Ten months later in June 2017, and 12 years after diagnosis of the original primary SSM, another excision of a further subcutaneous lesion near the original scar showed merging of atypical spindle cells with scarring suggesting progression to desmoplastic melanoma. In April 2018, another nodule excised near the scar showed features of desmoplastic melanoma extending to the margins of the specimen. A further excision in May 2018 contained more desmoplastic melanoma still showing a BRAF ${ }^{\mathrm{V} 600 \mathrm{E}}$ mutation, and this time appearing completely excised. In September 2020, the patient was referred to another hospital with intrathoracic lesions radiologically suspected as metastases. A biopsy was not

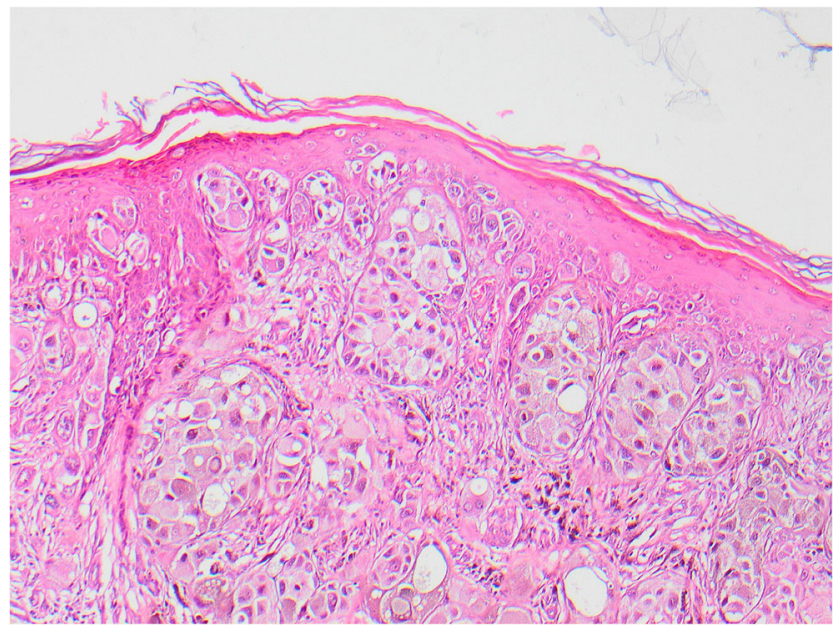

Fig. 1 The superficial part of the presenting melanoma in 2005 on the left leg showing pagetoid infiltration, characteristic of SSM

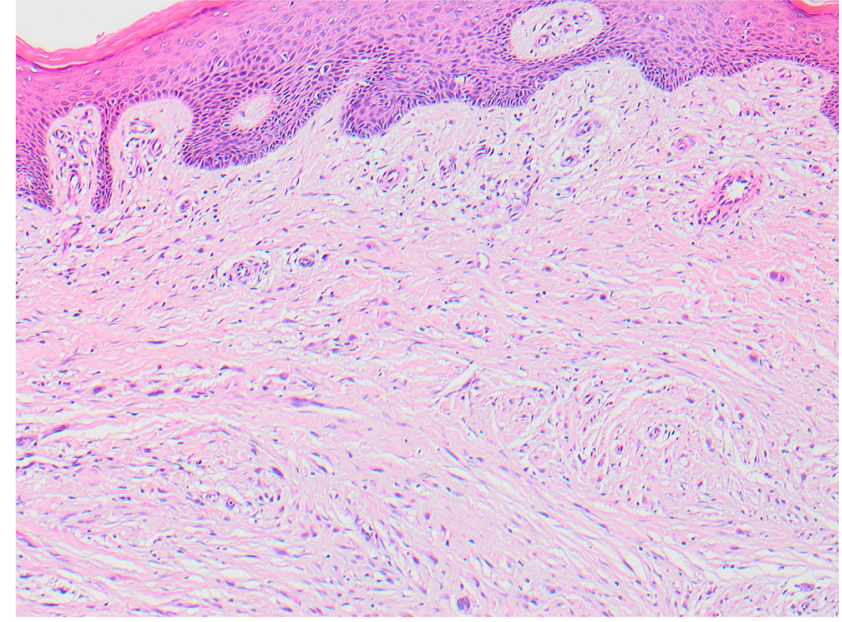

Fig. 2 The skin over the excised lesion in 2015 on the left leg, 10 years later showing the dermal proliferation of spindle cells with desmoplasia

proposed as the features were so highly consistent with metastatic melanoma.

\section{Discussion}

The histological interest of this case rests on the evolution over a 10-year period from primary SSM with nodal metastases to a spindle cell tumor with desmoplasia and without further metastasis but recurring locally with features of desmoplastic melanoma. The earlier metastases of epithelioid-type melanoma were to a groin node and an intransit metastasis in the popliteal fossa. These were completely excised.

Ten years after the original excision, the tumor recurred in the original scar with mixed epithelioid and spindle cell features and this then recurred again with spindle/desmoplastic features 13 years after the original

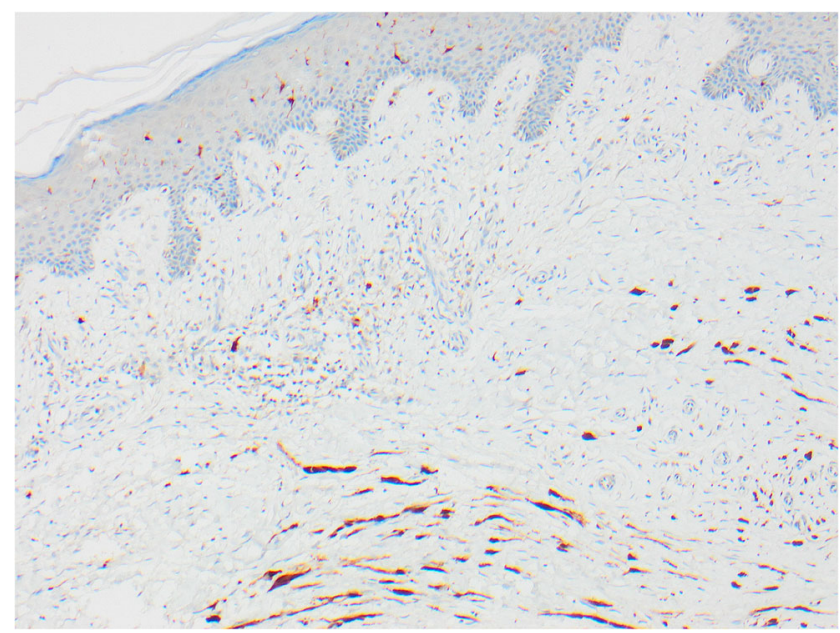

Fig. 3 The skin seen in Fig. 2 shows elongated spindle cells positive with S100 
presentation. It had the infiltrative pattern of a desmoplastic melanoma and a further complete excision was achieved. No perineural invasion or neutropism was identified. Not only did the histological features change with time but also the pattern of growth also changed from metastatic to locally infiltrative, although it still retained a BRAF mutation which is unusual in desmoplastic melanoma. Their molecular features typically include NF1 mutations as well as in CBL, ERBB2, MAP2K1, and MAP3K1 [5-7]. It appears that this melanoma underwent metaplastic change to resemble desmoplastic melanoma and acquired the associated biological characteristics, but it retained the BRAF mutation and eventually has reverted to biological behavior more typical of SSM.

The rate of mutations is higher than in most other melanomas, and the majority are said to be related to ultraviolet radiation mutagenesis [5]. Whether this applies to the large minority of desmoplastic melanomas that arise on infrequently exposed anatomical sites remains to be established, as does the genetic signature in mixed desmoplastic and other melanoma types.

Acknowledgements The authors would like to thank Professor Richard Marais who helped to secure project funding and provided useful discussion throughout.

Author contribution All authors contributed to the data acquisition, conception, and writing, and gave final approval.

Funding The work was supported by Cancer Research UK (Ref. C5759/ A20971).

Data availability Not applicable.

Code availability Not applicable.

\section{Declarations}

Ethics approval Approval was given by the Royal Surrey County Hospital Ethics Committee (07/Q190913).
Competing interests The authors declare no competing interests.

Open Access This article is licensed under a Creative Commons Attribution 4.0 International License, which permits use, sharing, adaptation, distribution and reproduction in any medium or format, as long as you give appropriate credit to the original author(s) and the source, provide a link to the Creative Commons licence, and indicate if changes were made. The images or other third party material in this article are included in the article's Creative Commons licence, unless indicated otherwise in a credit line to the material. If material is not included in the article's Creative Commons licence and your intended use is not permitted by statutory regulation or exceeds the permitted use, you will need to obtain permission directly from the copyright holder. To view a copy of this licence, visit http://creativecommons.org/licenses/by/4.0/.

\section{References}

1. de Almeida LS et al (2008) Desmoplastic malignant melanoma: a clinicopathologic analysis of 113 cases. Am J Dermatopathol 30(3): 207-215

2. George E et al (2009) Subclassification of desmoplastic melanoma: pure and mixed variants have significantly different capacities for lymph node metastasis. J Cutan Pathol 36(4):425-432

3. Busam KJ et al (2004) Cutaneous desmoplastic melanoma: reappraisal of morphologic heterogeneity and prognostic factors. Am J Surg Pathol 28(11):1518-1525

4. Scolyer RA, Thompson JF (2005) Desmoplastic melanoma: a heterogeneous entity in which subclassification as "pure" or "mixed" may have important prognostic significance. Ann Surg Oncol 12(3): 197-199

5. Rabbie R et al (2019) Melanoma subtypes: genomic profiles, prognostic molecular markers and therapeutic possibilities. J Pathol 247(5):539-551

6. Kim J et al (2012) BRAF, NRAS and KIT sequencing analysis of spindle cell melanoma. J Cutan Pathol 39(9):821-825

7. Davison JM et al (2005) Absence of V599E BRAF mutations in desmoplastic melanomas. Cancer 103(4):788-792

Publisher's note Springer Nature remains neutral with regard to jurisdictional claims in published maps and institutional affiliations. 